\title{
DE SEVILLA AL MAR. UNA MIRADA DESDE LA GEOGRAFÍA
}

\author{
Águeda Villa Díaz \\ Dra. geógrafa y Profesional de Arte Dramático. Profesora asociada de la U. Pablo de Olavide
}

https://dx.doi.org/10.12795/astragalo.2019.i26.03

\section{INTRODUCCIÓN}

Las características de la idea o concepto de bioregión, aparecen así definidas por Peter Berg ${ }^{1}$ en 1997:

Una biorregión puede ser determinada inicialmente a partir de la climatología, la fisiografía, la geografía de los animales y las plantas, la historia naturalyotras ciencias naturales descriptivas. Pero quien mejor describe los límites definitivos de una bioregión son las mismas personas que la han vivido, $y$ lo hacen a través del reconocimiento humano de las realidades de vivir-en-el-sitio.
Como se desprende de esta definición, una bioregión supondría una porción del espacio de la Tierra cuyos criterios de definición serían los elementos y procesos físicos naturales y humanos que la conforman como una unidad. Si bien, el reconocimiento efectivo como bioregión se lo otorgan sus propios habitantes, al asumir que esos elementos y procesos son los determinantes sobre los que se asienta su identidad y cuyo manejo viene permitiendo -a esa porción de la tierra-, ser habitada por los sucesivos grupos humanos que la han ocupado.

Por otra parte el biorregionalismo ${ }^{2}$ es un movimiento crítico, surgido como respuesta a la crisis ambiental motivada por el desarrollo generalizado del modelo de explotación industrial que se viene imponiendo en el conjunto

2 http://www.aecid.es/galerias/revistas/descargas/ repositorio/obrs/libro-selba-bibliot-coop-00000190.pdf (Consultado 3-11-2019). 
del planeta desde el siglo XVIII, y que está poniendo en peligro el poder disponer de recursos imprescindibles para la vida humana, como el agua, el suelo y la propia calidad del aire. En parte este movimiento coincide con otros modelos de análisis, como el ecologismo o la ecología política urbana (EPU) ${ }^{3}$, en aspectos que redundan en la necesidad de definir y acordar una manera distinta de planificar y gestionar un territorio.

Como telón de fondo de este tipo de análisis, debe estar la superación de la creencia de que la humanidad está fuera y por encima de la naturaleza, sustituyendo así, la lógica dualista naturaleza-cultura, por el entendimiento de que los procesos naturales y humanos van siempre unidos, funcionan de forma dialéctica y pueden caminar en distintas direcciones, por lo cual, el progreso no tiene que ser obligatoriamente lineal.

Desde estos postulados y teniendo en cuenta la definición de biorregión señalada con anterioridad, en el análisis que pueda llevar a la definición y compresión de una biorregión y su sistema de funcionamiento, es muy importante la consideración de los que son sus determinantes y procesos físicos y humanos. En este marco es muy útil la geografía, entendiéndola como una disciplina que, aunque cuenta con diversas especialidades, se sigue manteniendo en la frontera de muchos conocimientos y para la cual, sigue siendo fundamental la observación directa en el campo. Trabajar desde la geografía permite ir aprendiendo de las ciencias de la tierra para, uniéndolas con las humanidades y ciencias sociales, ir construyendo, ordenadamente, la imagen completa del rompecabezas espacio-territorial-cultural a estudiar. Un or-

$3 \mathrm{https://dialnet.unirioja.es/servlet//}$ articulo?codigo=4763771 (Consultado 5-11-2019). den que debe comenzar por el estudio y comprensión de las características naturales de cada espacio y los procesos que de ellas derivan, entendiéndolas como el soporte de los usos y formas de vida de sus sucesivos habitantes.

El objetivo de este artículo no es otro que realizar una aproximación a la ciudad de Sevilla teniendo en cuenta los condicionantes físico-naturales y humanos de su contexto espacial que explican su presencia y evolución; además de que, secularmente, la ciudad viene ejerciendo una función como de umbral en el río Guadalquivir. Y, en esta función de marcar la puerta al gran valle bético, las actuales marismas del Guadalquivir actúan a modo de atrio o pórtico, protegiendo y acompañando a la ciudad en su doble relación con el río y el mar. Mirando desde esta posición, ciudad-río-marismas mantienen una relación directa e imprescindible, entrelazando su destino físico natural, histórico, cultural y social. Una relación que con el río ha ido cambiando a lo largo de la historia, aunque su presencia sea siempre determinante para la ciudad sus vecinos y visitantes. Mientras con las marismas, la percepción de esa interdependencia se ha ido debilitando hasta casi olvidarse en la actualidad.

\section{DE SEVILLA AL MAR. CONDICIONANTES FÍSICOS Y HUMANOS}

La presencia de Sevilla está indisolublemente asociada al río Guadalquivir que, con sus aproximadamente $657 \mathrm{~km}$ de longitud, articula de este a oeste la región andaluza desde su nacimiento en la sierra de Cazorla hasta su desembocadura en el océano Atlántico. 
Desde su localización en el suroeste de la península ibérica, esta ciudad ejerce de capital de la Comunidad Autónoma de Andalucía, siendo su entorno socioterritorial conocido como la Baja Andalucía donde confluyen las provincias de Huelva, Sevilla y Cádiz. Espacialmente se asocia al tramo último del Guadalquivir, correspondiéndose con su antigua ría y actuales marismas: una amplia llanura de unos $3000 \mathrm{Km} 2$ y forma triangular, donde Sevilla ejerce como vértice inicial, a partir del cual va abriéndose hasta llegar a los cordones dunares de Doñana que, a modo de telón de fondo, separan las marismas del mar.

Por su situación geográfica, Sevilla funciona como una doble bisagra. A escala regional, la posición de la ciudad en el entorno del estrecho de Gibraltar, concretamente en el centro del golfo de Cádiz, la convierte en un hito estratégico entre el Mediterráneo y el Atlántico dado los continuados flujos de personas, mercancías e ideas que se vienen dando por estas aguas desde tiempo inmemorial. Durante la antigüedad, este papel de parada intermedia o correa de transmisión, se realizaba -oficialmente- en tierra de nadie, en la frontera, pues el primero de estos mundos -el Mediterráneo-, tenía su fin en las columnas de Hércules y el segundo -el Atlántico- en el cabo de San Vicente.

$Y$, en relación con el Guadalquivir, la ciudad funciona como el gozne que fija a la par la entrada del río hacia el interior del valle y la salida de éste hacia el mar. Para conseguir esta doble función sus fundadores eligieron un emplazamiento muy concreto, un pequeño promontorio situado en la más joven de las terrazas del río y, justo, al inicio de la llanura aluvial del Guadalquivir. Este emplazamiento convierte a la ciudad en una suerte de umbral, un puerto interior y abrigado, donde se vienen realizando todo tipo de intercambios y trasiegos, una multiplicidad de transbordos mercantiles y vitales con alcance regional, nacional e internacional, atendiendo a diferentes etapas históricas, como ha estudiado, entre otros autores, Antonio Domínguez Ortiz.

Los condicionantes físico-naturales del emplazamiento de Sevilla y su solar están determinados por el proceso de colmatación del antiguo estuario del Guadalquivir, cuya evolución durante el Holoceno se representa en la Fig.1. El primer paso de esta secuencia, 1.a, muestra la situación de hace unos 6500 años, cuando las aguas del mar cubrían por completo la gran ensenada marina formada en la desembocadura del Guadalquivir fruto del máximo avance del mar (transgresión Flandiense). El segundo hito, 1.b, está fechado hace unos 30002800 años, intervalo de tiempo coincidente con la fundación de la ciudad y durante el cual esta ensenada presenta una morfología distinta: las aguas libres del océano han retrocedido, tras el inicio de dos procesos paralelos y enfrentados que finalizaran con la colmatación de las marismas. Los procesos serían, por una parte y fruto principalmente del arrastre de los sedimentos del río, la paulatina consolidación de las llanuras aluviales más cercanas a la ciudad; mientras por otra y derivado de la dinámica marina, el desarrollo de las flechas litorales, comenzando así el cierre del estuario por el sur.

El esquema 1.c, contemporáneo con el periodo Turdetano-Romano y desarrollado entre los años 2390 y 1600, ofrece una visión muy consolidada de las marismas, reduciéndose las aguas libres a una pequeña ensenada final, identificada como el Lacus Ligustinos, repetidamente citado en las fuentes clásicas latinas. El 

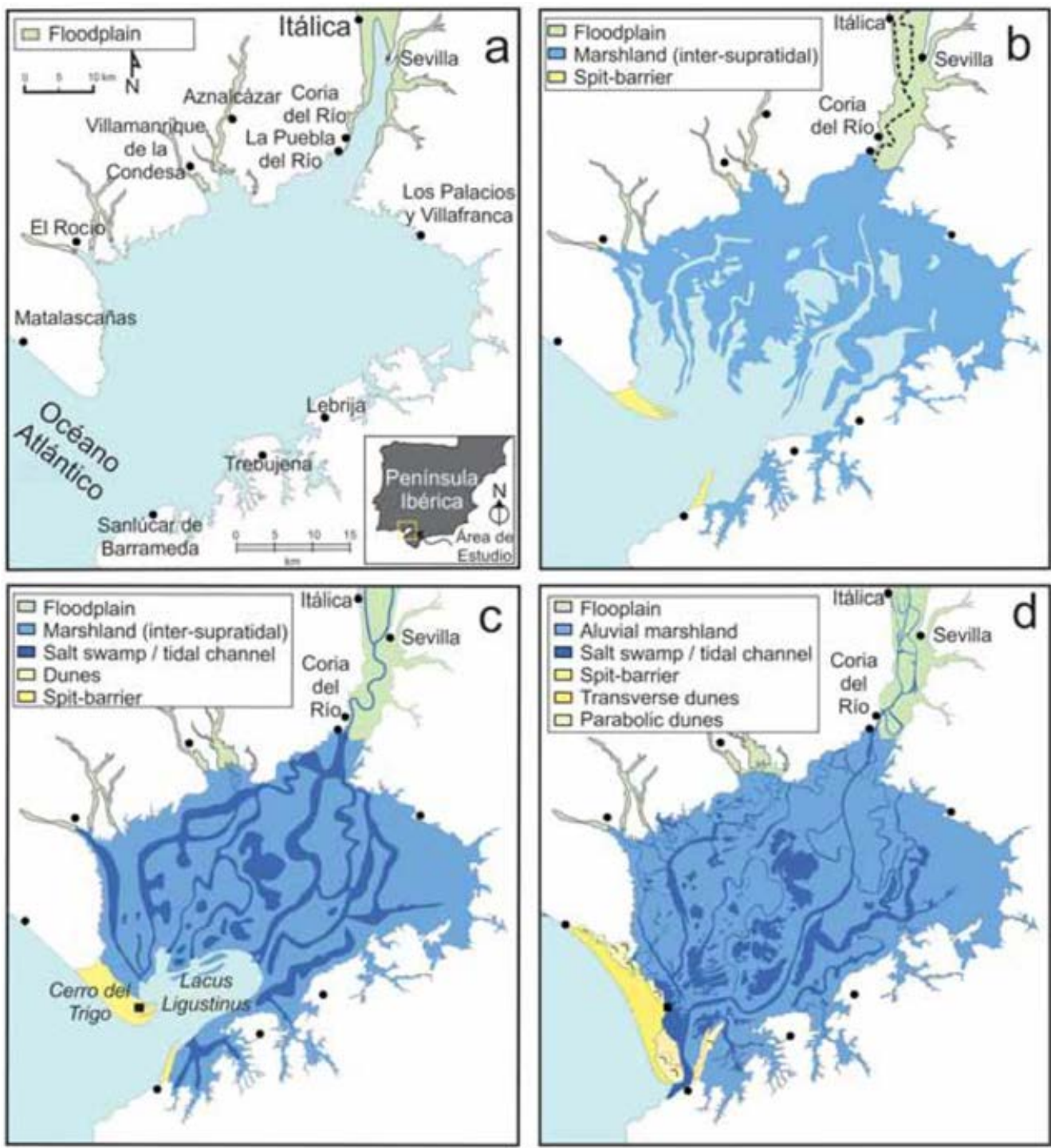

Fig. 1. Reconstrucción tentativa de la evolución del conjunto de la desembocadura del Guadalquivir durante la segunda mitad del Holoceno. Fuente: Evolución de la Ilanura aluvial del bajo Guadalquivir durante el Holoceno medio-superior. Geoarqueología y reconstrucción paleogeográfica de la vega de Itálica (Sevilla, España). Fuente: Evolución de la Ilanura aluvial del bajo Guadalquivir durante el Holoceno medio-superior. Geoarqueología y reconstrucción paleogeográfica de la vega de Itálica (Sevilla, España). 2018

último paso, 1.d, o fase resultante, se correspon- llo de los cordones de dunas vivas que dejan a de con el cierre final de las flechas y el desarro- las marismas sin la influencia directa del mar. 
La morfología que muestra el esquema 1.d, en comparación con la anterior 1.c, refleja también la intensa actividad hidráulica que ha transformado el Bajo Guadalquivir: rectificaciones en algunos tramos de los cauces, cortas de meandros, encauzamientos, etc. Son obras de gran calado desarrolladas en los últimos siglos y que se corresponde con el momento actual de este río, paulatinamente domado en consonancia con intereses de la ciudad y que fluye con dificultad por unas marismas ya senescentes.

La secuencia de la Fig. 1 recorre el proceso de conformación del soporte físico-natural de Sevilla y sus espacios aledaños, cuyos materiales de finales del terciario (arcillas limosas, areniscas, arenas y limos), se disponen en distintas capas superpuestas acompañándose de los depósitos detríticos de las terrazas fluviales y las acumulaciones de materiales finos de la llanura aluvial, originados ya en el cuaternario. A estas características geomorfológicas, las complementan unos rasgos climáticos caracterizados como de clima mediterráneo con influencia atlántica, que responde a los siguientes valores para la serie 1981-2010 años (Sevilla, estación aeropuerto (AEMET) ${ }^{4}$ : temperatura media de $19,2^{\circ} \mathrm{C}$ y una precipitación 539 mm media anual.

Concretando lo referido a sus condicionantes físico-naturales, puede decirse que Sevilla nace prácticamente en el agua, en un ambiente movedizo, de clima suave, sobre un soporte geológico muy reciente y sujeto a un proceso geomorfológico dominado por la inestabilidad y el dinamismo. Estos condicionantes que derivan de su emplazamiento en la interce-

4 https://www.aemet.es/es/serviciosclimaticos/ datosclimatologicos/valoresclimatologicos? $\mathrm{l}=5783 \& \mathrm{k}=\mathrm{a}$ nd (Consultado 10-12-2019)

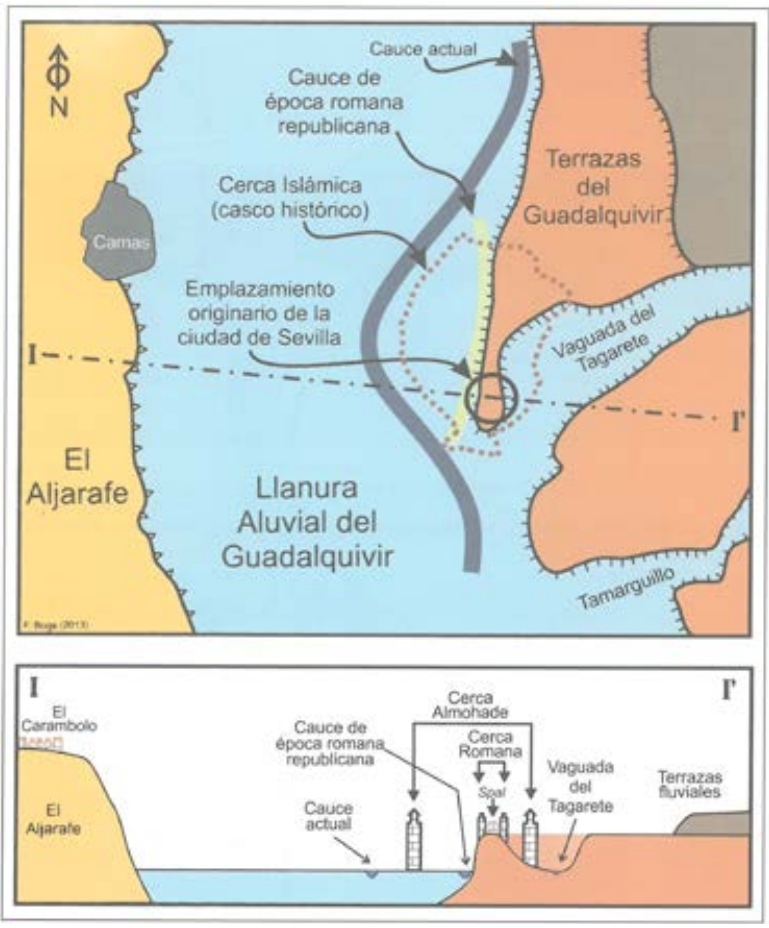

Fig. 2. Reconstrucción idealizada de la planta y sección de la llanura aluvial del Guadalquivir, en relación a la evolución de la ciudad de Sevilla. Fuente: La ciudad en época protohistórica, antigua y andalusí. 2014

sión entre el río Guadalquivir y su ría, dotan a este lugar de las condiciones precisas necesitadas por sus primeros moradores, que accedieron hasta allí en barco hace ya casi 3000 años, tras atravesar una ensenada que ofrecía las condiciones esquematizadas en la Fig.1.b.

En cuanto a sus fundamentos históricos y, de acuerdo con José Luís Escacena Carrasco ${ }^{5}$, Sevilla es una fundación fenicia fechada en el siglo IX a.C, cuyas características se reflejan en la Fig. 2, que reconstruye de forma idealizada la

5 ESCACENA, J.L. (2014): "Sevilla Fenicia” 


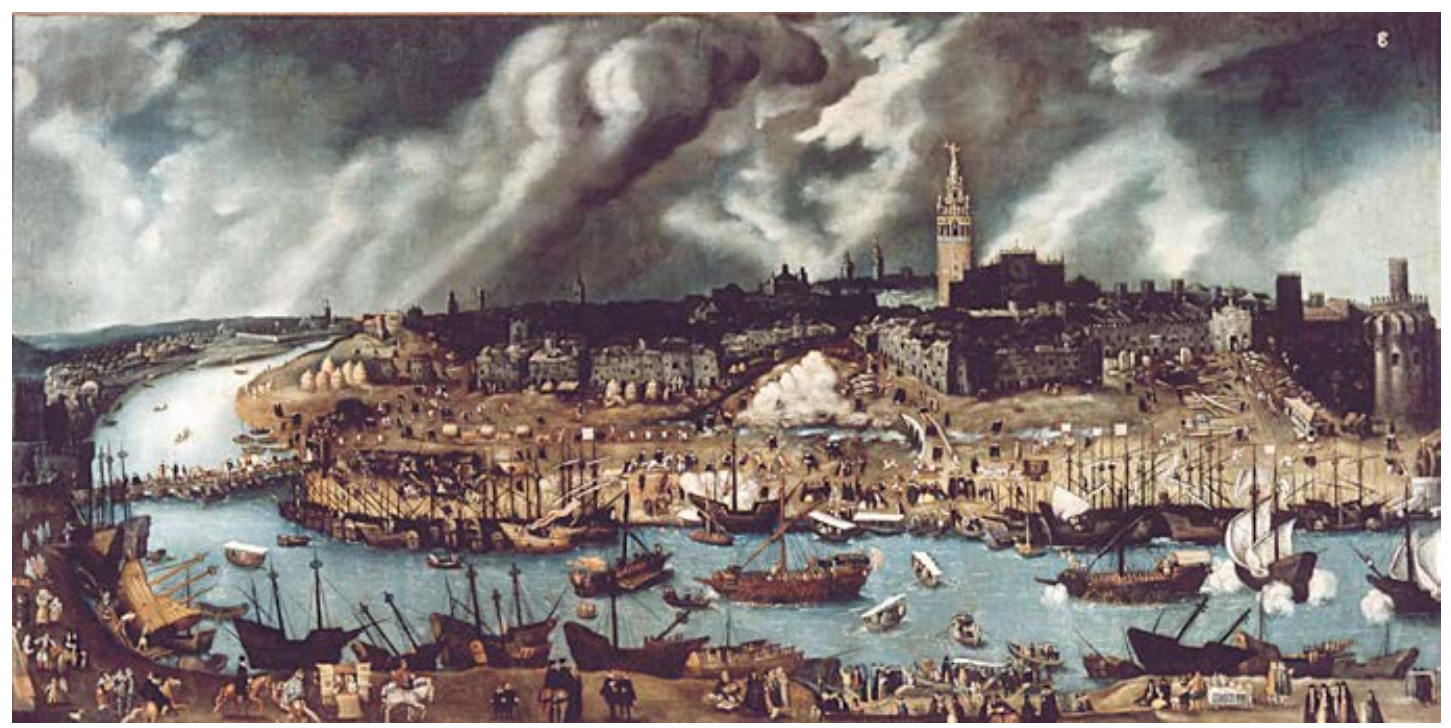

Fig. 3. Vista de la ciudad de Sevilla finales del siglo XVI. Óleo sobre lienzo, 146 x $295 \mathrm{~cm}$. Alonso Sánchez Cohello. https://www.museodelprado.es/coleccion/obra-de-arte/vista-de-la-ciudad-de-sevilla/df3adb65-3fbd-4438-8c06-d75e8685f117 (Consultado 20-11-2019) (atribuido). Fuente: Museo del Prado

evolución la ciudad desde su fundación hasta la Baja Edad Media ${ }^{6}$.

El esquema deja patente cómo el asentamiento inicial constaba de dos núcleos que ocupaban orillas opuestas y cada uno cumplía funciones específicas. Al oeste y encaramado en El Aljarafe, a salvo de aguas imprudentes, se encontraba el espacio sagrado, el santuario de Astarté excavado en el Carambolo; mientras al este y en la zona baja, se encontraba el núcleo dedicado a la actividad portuaria y germen de la ciudad actual. Tanto en la planta como en el perfil, se puede observar su emplazamiento original entre dos ríos. Un emplazamiento mesopotámico y no exento de osadía, dada la fragilidad de esa estrecha península que emergía no más de 19 metros sobre el nivel del mar, alargándose desde

6 BORJA, F. (2014): “Geoarqueología urbana en Sevilla”. la terraza inferior del Guadalquivir para separar el curso de este río de la boca del arroyo Tagarete. El asentamiento, nombrado inicialmente como Spal y cuyo solar discurría entre las actuales Cuesta del Rosario y la calle Mateos Gago, nació en un contexto de desarrollo del mundo tartésico, coincidiendo con el auge de otros asentamientos tanto en el golfo de Cádiz como en el norte de Marruecos. Spal se mantendrá como un puerto importante hasta el siglo VI a.C., cuando la crisis del orden mediterráneo acarrea la paulatina decadencia de Tartesos dando paso a la etapa turdetana de la ciudad, ésta ya asociada al asentamiento de la zona baja, tras el abandono y ruina del santuario de Astarté.

Esta etapa se cerrará a finales del siglo I aC. cuando la ciudad, renombrada como Hipalis, entre a formar parte del circuito romano y 

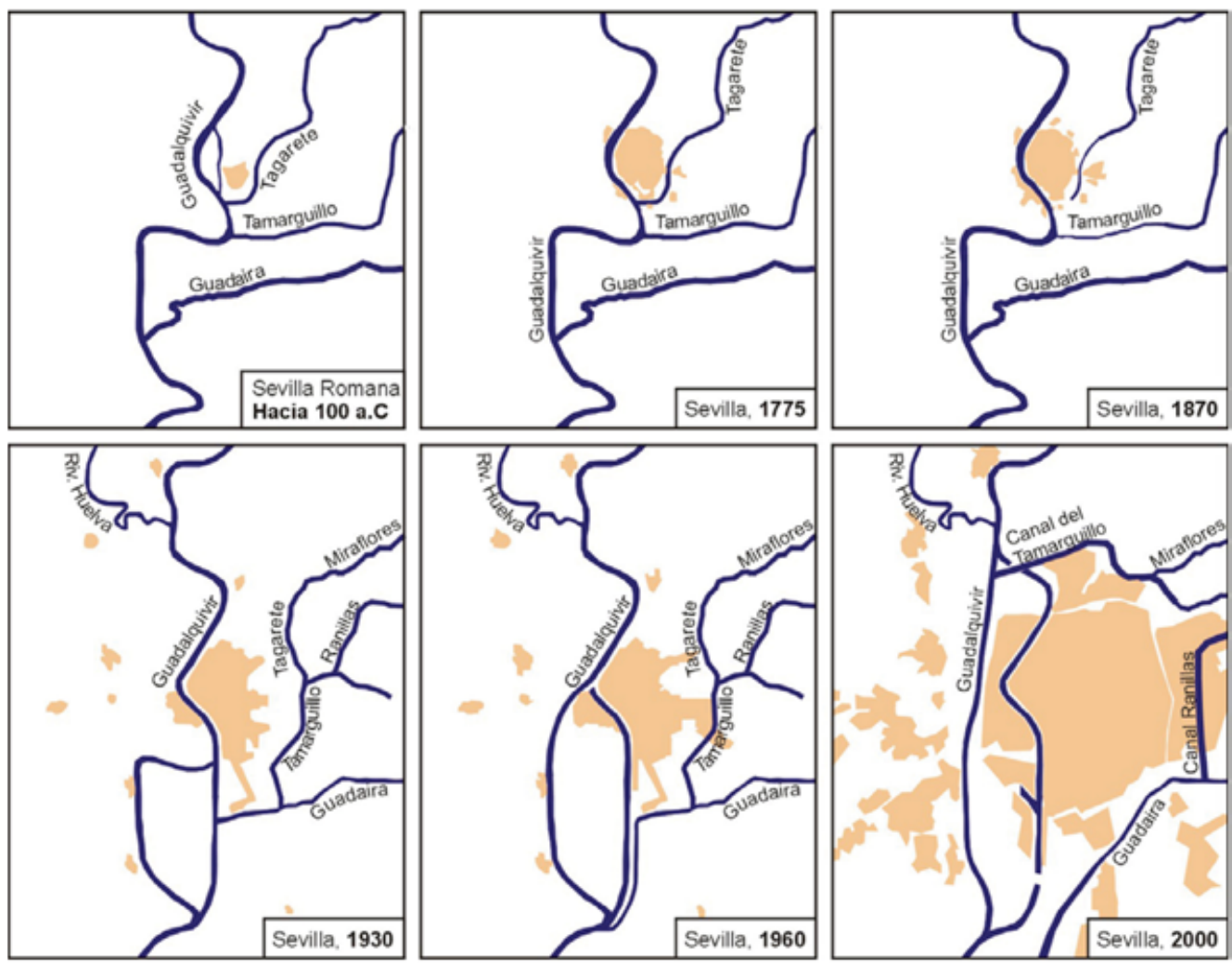

Fig. 4. Transformación de la red fluvial de Sevilla. Fuente: Paisajes Patrimoniales de España (2018)

recobre su papel como puerto de interés para la salida de los productos de la Bética hacia Roma, especialmente el aceite de oliva. Desde esa fecha el solar de Sevilla ha ido creciendo de forma permanente, en función de los sucesivos retranqueos del Guadalquivir y de la transformación del conjunto de arroyos que desembocan en él por su margen izquierda.

Como muestra la Fig. 4, desde su fundación hasta 1775 , la ciudad se mantiene en el interfluvio Guadalquivir-Tagarete, si bien, en esa fecha ya ha sido objeto de una intervención importante: el aterramiento del curso urbano antiguo del Guadalquivir realizado durante la Baja Edad Media. Este aterramiento dio lugar a la zona portuaria del Arenal, configurándose lo que sería el escenario de la Sevilla americana y una de las vistas más reconocidas de esta ciudad como paisaje histórico y patrimonial, reflejada en la obra de artistas como Sánchez Cohello?.

En el esquema correspondiente a 1870, la ciudad deja de estar completamente perimetrada por los dos cursos fluviales citados, pero quizás, lo más destacable de esta fecha en relación al paso siguiente de 1930, esté en los importantes cambios que presentan tanto el

7 GARCÍA GARCÍA, A. http://revistamito.com/paisajesurbanos-la-sevilla-de-la-edad-moderna-traves-de-lasfuentes-graficas/(Consultado 28-12-2019) 
solar sevillano como los cursos de los arroyos y el trazado del Guadalquivir. En solo 60 años, el grado de transformación de la red hidrográfica asociada a la ciudad es ingente, reflejando el poder de transformación adquirido ya por la tecnología hidráulica, unos avances imprescindibles para dominar el Guadalquivir, que mantuvo un puente de barcas para unir Sevilla con Triana hasta finales del XIX ${ }^{8}$.

A partir de esta fecha las intervenciones se intensifican, dando como resultado final el esquema fechado en el año 2000, donde se pone de manifiesto el completo rediseño del Guadalquivir y de los arroyos de su margen izquierda. Estas actuaciones han conseguido evitar las inundaciones, la última fue el 25 de noviembre de 1961; y sanear un significativo porcentaje de terreno facilitando el crecimiento urbano hacia el suroeste. En la actualidad puede decirse que Hoy el Guadalquivir cuenta en Sevilla con un cauce real domesticado y trasero y con una dársena urbana que funciona como puerto como escaparate y gran vía de la ciudad monumental y turística y como reputado espacio deportivo (García García, Delgado Bujalance y Ojeda-Rivera, 2007: 295)

Y si el crecimiento urbano ha conseguido engullir parte del sistema fluvial de la ciudad, otorgando al actual curso urbano del Guadalquivir otras funciones que han opacado a la portuaria, la relación de la ciudad con las marismas o antigua ría del Guadalquivir se encuentra invisibilizada, fracturada, como si el río y lo que significa se ciñera a la dársena urbana. Desde la óptica de la biorregión esta forma de relación supondría una castración para la

8 Para conocer estas intervenciones se puede consultar La obra hidráulica en la cuenca baja del Guadalquivir. (Siglos XVIII-XX). Gestión del agua y ordenación del territorio, del geógrafo Leandro del Moral Ituarte. ciudad y sus ciudadanos, proponiendo que para conseguir un conocimiento que fundamente una planificación adecuada a la problemática actual, es necesario flexibilizar los límites urbanos y analizar a una escala que permita incorporar los condicionantes naturales básicos.

En el caso de Sevilla, esa escala podría ser el ámbito de la Fig.1, donde se sustenta esa relación secular río-ciudad-marismas. En el momento actual y tal como se muestra en la Fig. 1.d, las marismas del Guadalquivir comprenden una llanura extendida a ambas márgenes del río, cuya morfología es fruto de sus determinantes naturales y la intervención humana. Estas marismas, muy colmatadas y cuyas mayores alturas no superan los 3 metros sobre el nivel del mar, presentan una compartimentación interna derivada del discurrir de los tres brazos principales que dirigían sus aguas hacia el Atlántico.

La margen derecha del Guadalquivir concentra más del $60 \%$ del total de las marismas, todas incluidas en el ámbito de la Reserva de la Biosfera de Doñana ${ }^{9}$ y entre las cuales se pueden diferenciar marismas transformadas, semitransformadas y seminaturales. Estas últimas presentan el mayor índice de protección ambiental, pues mantienen unos valores que son el origen de los reconocimientos de Doñana como patrimonio natural. El primero de estos reconocimientos fue su declaración como Parque Nacional en 1969, y, desde esa fecha y de forma paralela al paulatino reconocimiento de la pér-

9 La figura de Reserva de la Biosfera, se crea en 1974 en el marco del Programa MaB (Hombre y Biosfera) de la UNESCO. El objetivo de esta figura es abordar de una manera integrada la preservación de los recursos naturales y el desarrollo social y económico de sus habitantes. De ahí que, en las reservas, sea fundamental que se impulse y apoye el desarrollo sostenible y la participación activa de su población. 


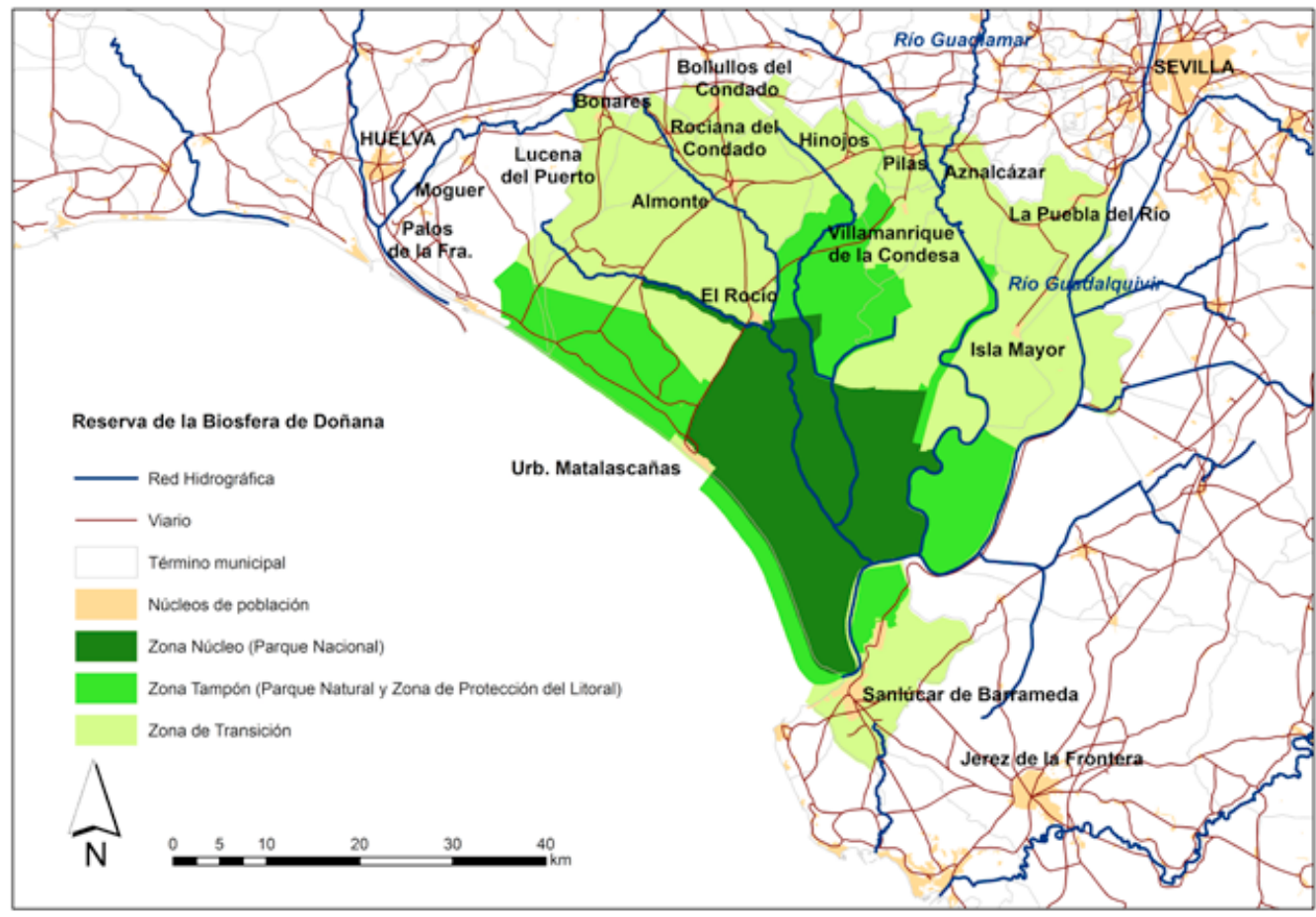

Fig. 5: Ámbito de la Reserva de la Biosfera de Doñana. Fuente: Cesar López (2018)

dida de biodiversidad y otros problemas ambientales que vienen dándose en el conjunto del planeta, Doñana ha ido aumentando en superficie a preservar y en número de reconocimientos autonómicos, estatales e internacionales ${ }^{10}$.

Como principales características físiconaturales, las marismas seminaturales mantie-

10 Doñana es uno de los espacios con mayor número de declaraciones y reconocimientos de sus valores naturales y ambientales, pudiéndose destacar: el Espacio Natural Doñana (Parque Nacional y Parque Natural); parte del Paisaje Protegido del Guadiamar; varios Monumentos Naturales; distintas Zonas de Especial Conservación ZEC de la Red Natura 2000; humedal RAMSAR; Patrimonio Mundial y Reserva de la Biosfera, estas tres últimas de UNESCO; y, cuenta también con reconocimientos a su gestión como el Diploma Europeo o su inscripción en la Lista Verde de la Unión Internacional para la Conservación de la Naturaleza (UICN). nen parcialmente su funcionamiento natural y pequeños accidentes topográficos, favoreciendo la diversificación de ambientes para el desarrollo de la vida silvestre ${ }^{11}$. La vegetación propia de la marisma está muy relacionada con la cantidad y salinidad del agua pudiéndose encontrar bayuncos, castañuelas, distintos tipos de almajos y algunas gramíneas. Para la fauna, su papel más destacado está en servir de paso para más de dos millones de aves en sus tránsitos migratorios entre Europa y África.

Limítrofe a estas marismas seminaturales, cuya principal función es aportar servicios

11 Destacando en la planitud aparecen vetas, vetones y paciles como los puntos más altos y últimos en inundarse; en contraposición a los lucios y ojos, lugares especialmente bajos que mantienen el agua durante más tiempo. 
ambientales a la sociedad en general, complementados con algunos servicios económicos, se encuentra la Isla Mayor, fácilmente reconocible en la Fig. 5 por su discurrir de norte a sur como una amplia y larga lengua.

Esta isla ocupa una posición central en el estuario, distribuye sus tierras entre los términos municipales de Puebla del Río e Isla Mayor e, históricamente, ha mantenido una estrecha relación con la ciudad (siglos XIII-XIX). Tras la conquista cristiana de Sevilla (1248), la Isla Mayor pasó a formar parte del término municipal de la Puebla del Río mientras el concejo sevillano será el encargado de la organización y gestión de sus recursos. Al aprovechamiento ganadero, reconocido como el más importante, se le irán uniendo otros como la recolección y quema de almajos para la fabricación de jabón en las almonas de Sevilla, la pesca de caños, la caza o la agricultura de matos y huertas.

Este sistema de gestión, propio de la forma de vida tradicional, permanecerá hasta finales del siglo XVIII, iniciándose desde esta fecha sucesivos intentos de transformación de estas tierras con dos objetivos: las mejoras en la navegabilidad del río y la puesta en producción de las tierras. El Estado será el encargado de abordar esta labor para lo cual se apoyará en un cuerpo legislativo específico, que permitirá la intervención de grandes empresas extranjeras propietarias o concesionarias de las tierras que -a modo de compañías coloniales- juegan un papel decisivo en la conformación del arrozal ${ }^{12}$.

En la Isla Mayor, desde principios del siglo XIX se habían acometido obras para facilitar la navegación, pero será en 1923 cuando

12 Para profundizar en la construcción del arrozal en la Isla Mayor se ofrecen en la bibliografía trabajos de distintos autores/as. la Compañía de las Islas del Guadalquivir conocida como de Los Ingleses comienza con la desecación y desalinización de las tierras, iniciando sus experimentos con el cultivo del arroz. Esta compañía puso las bases del actual orden territorial marismeño pues reorganizó su estructura y sistema de relaciones con el trazado de los primeros canales y el viario, incluyendo un tramo de ferrocarril; introdujo la mecanización y levantó talleres, barracones y diversos tipos de alojamientos que culminaron en poblados entre los que destaca Alfonso XIII, inaugurado en 1927 por el propio rey.

En plena Guerra Civil, en 1937, se retoma la puesta en cultivo de arroz de la Isla Mayor usando como instrumento la empresa andaluza R. Beca y Cía. Industrias Agrícolas. Esta compañía creará un mundo nuevo siguiendo un proceso cargado de urgencia, donde fue determinante contar primero con el apoyo de los mandos del ejecito sublevado, para -con posterioridad a la contienda- contar con el apoyo de gobierno de Franco y convertirse en una empresa de interés nacional.

La Isla Mayor irá tornándose en la Isla del arroz en las décadas centrales del siglo pasado, construyéndose un nuevo paisaje productivo y humano, donde fue determinante -por parte de la compañía- la captación de una población que fue llegando en sucesivas etapas, desde distintos puntos de origen y con distintas condiciones de partida; circunstancias que dieron lugar inicialmente a situaciones conflictivas, especialmente entre andaluces y valencianos. A finales de los años setenta, este mundo nuevo aparecía ya consolidado, con el arrozal como el gran protagonista y salpicado de unos poblados pensados para la fijación definitiva de la población, de ahí sus dotaciones de edificios públicos y administrativos, viviendas, colegios 


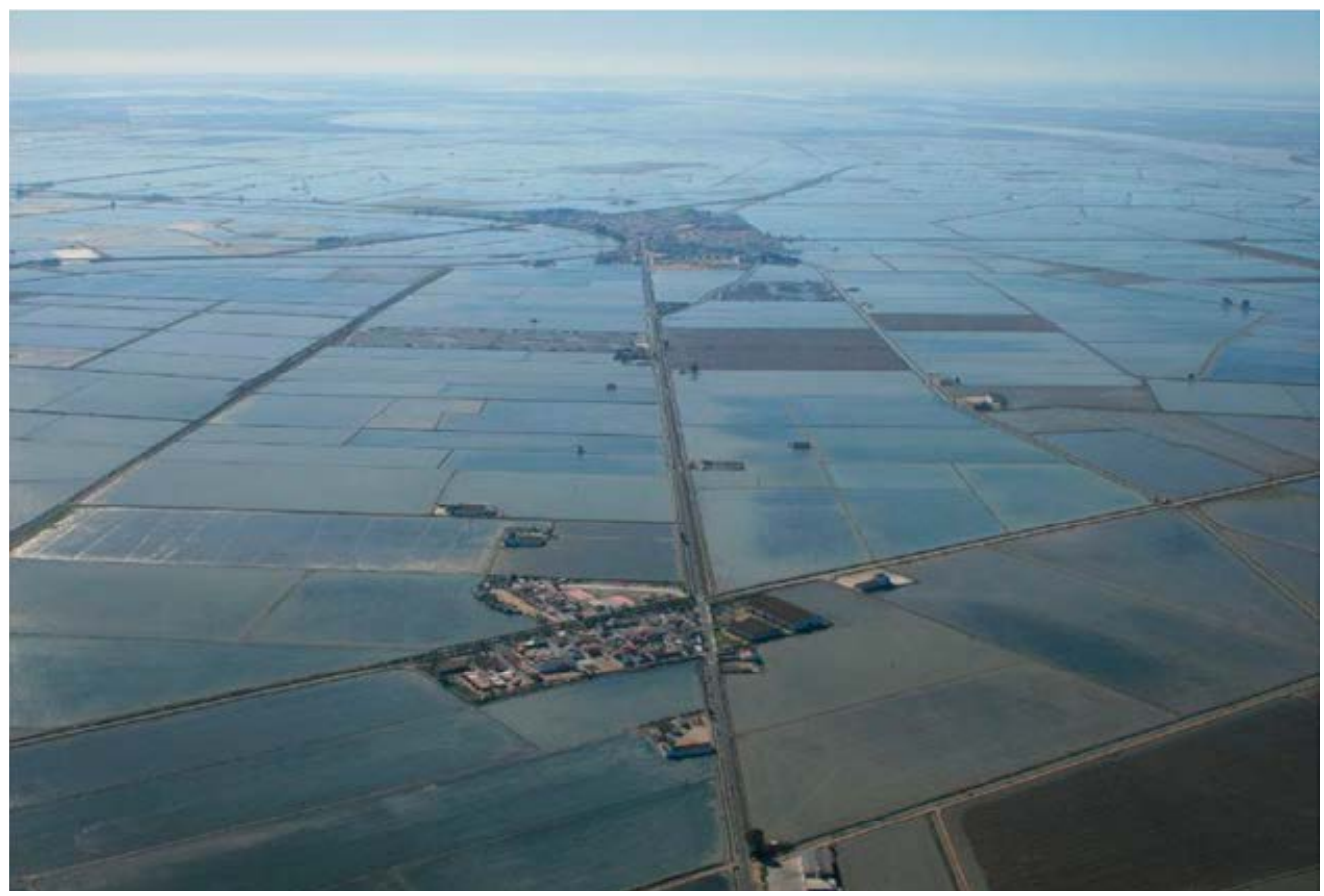

Fig. 6: Al fondo, vista del casco urbano de Isla Mayor. En primer término, Alfonso XIII. Fuente: https://www.google.com/

e iglesia. De todos los poblados integrales, será en Villafranco del Guadalquivir donde se irán concentrando población y funciones, pasando a convertirse en la capital de la Isla del arroz y, en el escenario donde se forjará la urdimbre isleña y se impulsará la independencia del actual municipio de Isla Mayor ${ }^{13}$, conseguida en 1994.

Enclavado en el centro de la Isla Mayor, el municipio del mismo nombre se individualiza en el inmenso arrozal y su asentamiento principal, situado a 5 metros sobre el nivel del mar, parece-como Sevilla en su origen- emerger del agua durante gran parte del año, percibiéndose

13 La superficie de este municipios es de $114,38 \mathrm{~km} 2$ y su población ronda los 5.900 (2019), distribuidos entre sus dos núcleos, Isla Mayor y Alfonso XIII. El nombre de Isla Mayor para el municipio fue elegido por los vecinos en un referéndum (1998) como un hábitat concebido por y para el arroz. Pero el municipio de Isla Mayor es algo más que un mundo nuevo, terminado y con el arroz como monocultivo, pues en las últimas décadas ha tenido que enfrentarse a una serie de dinámicas y conflictos relacionadas con la evolución del propio cultivo y con la protección ambiental derivada de su inclusión y/o vecindad con los espacios protegidos de Doñana.

En relación con el arroz las dinámicas han derivado de las sucesivas crisis del cultivo y los cambios en las políticas de la UE, entre las que se encuentra el aumento de cautelas para la seguridad alimentaria. $Y$, en cuanto a los conflictos que dieron luga a un antidoñanismo latente, se pueden citar la mortandad de aves, la aparición y el desarrollo del cangrejo rojo americano, el uso de agua subterránea 

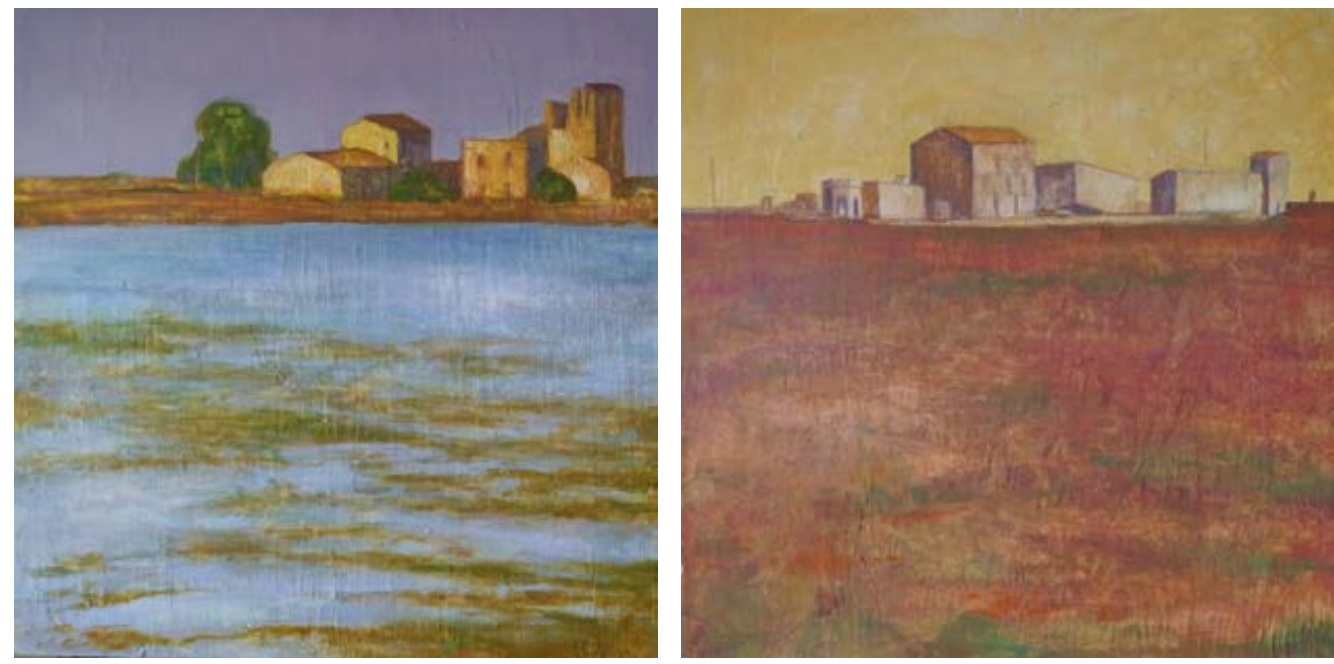

Fig. 7: Edificaciones arroceras abandonadas. Arqueología del arrozal / y ll. Carmen Andreu (2013), temple vinílico sobre tabla, $60 \times 60 \mathrm{~cm}$.

para el riego del arroz, la abundancia de aves en las tablas con el consiguiente problema para el cultivo, y el grave accidente que supuso la rotura y derrame de los lodos tóxicos de la presa de Aznalcóllar. Para la solución o amortiguamiento de estos conflictos se han desarrollado unas estrategias que combinan distintos tipos de acciones. Por una parte, se han incorporado nuevas tecnologías orientadas hacia una mayor eficiencia y eficacia en el uso del agua (introducción de ordenadores, sensores climáticos, laser, GPS, medidas de reciclaje de aguas); así como el desarrollo de ensayos para las mejoras de las semillas y la producción de arroz ecológico y/o integrado. Y, por otra parte, el tejido social de Isla Mayor, ha sido capaz de trabajar en positivo, pasando del enfrentamiento a la negociación para encontrar los puntos comunes y establecer medidas que articulen el mayor número de intereses. Un funcionamiento inclusivo donde el cangrejo rojo americano tiene casi un papel simbólico, pues ha pasado de ser un problema compartido por los arroceros y los gestores de Doñana, a una especie asimilada gastronómicamente que se recoge, se exporta y protagoniza una fiesta local.

Esta manera trabajar indica la existencia de una sociedad cohesionada, adaptativa o resiliente; que ha iniciado un camino propio y acumula ya suficiente madurez para contar con un patrimonio propio y trasmitirlo como herencia. Todos estos aspectos se reflejan en el paisaje isleño, que quizás sea su elemento patrimonial por excelencia y donde, con más claridad, parece residir la identidad actual de esta sección de las marismas de la margen derecha del Guadalquivir y la autoctonía de sus vecinos: ...Los griegos decían que esta intensa y viva relación de los hombres con los lugares les hace "paisanos", "autóctonos", en su sentido más literal. El grupo humano, clan o tribu, constituye una sola entidad con su país de origen, $y$, por ellos, emigrar es una ruptura profunda: un trasplante, una pérdida de sustancia... (Dardel, 1952:112). 


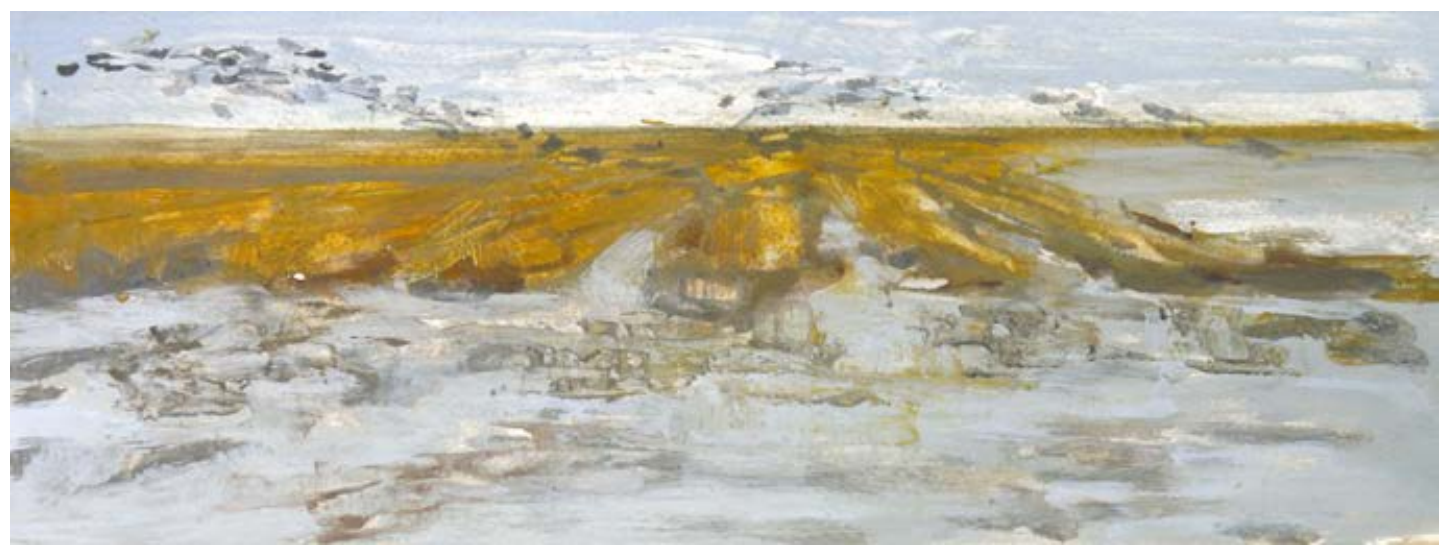

Fig. 8: Aves en las marismas arroceras después de la cosecha. Revuelo en las marismas. En busca del cangrejo rojo. Carmen Andreu (2013), temple de huevo sobre papel, $40 \times 15 \mathrm{~cm}$.

A través de una mirada atenta a este paisaje, pleno de fuerza y vigor como lo muestra la película Isla Mínima ${ }^{14}$, puede observarse todo su proceso de construcción sorprendiendo, en primer lugar, el protagonismo mantenido por sus componentes físicos y naturales a pesar de la potente intervención humana de que ha sido objeto. Un protagonismo basado en la permanencia de los elementos donde radica el carácter anfibio de esta isla: el agua, ahora dominada, sigue siendo el elemento protagonista; igualmente pervive la planitud, pues continúa anegándose y presentando una marcada estacionalidad actualmente dependiente del cultivo. Por otra parte, esa mirada al paisaje isleño también muestra el resultado de su proceso histórico y socioproductivo, traducido en el dominio de la línea recta como eje de ordenación, y en la presencia de unos asentamientos que rompen la monotonía del cultivo aportando cierta verticalidad $y$, sobre todo, la certeza de

14 Este paisaje ha sido objeto de interés por distintos artistas, entre los que pueden citarse novelistas como Alfonso Groso, fotógrafos como Atín Aya y pintores/as como Paco Broca y Carmen Andreu. la definitiva humanización del antiguo estuario del río Guadalquivir.

E, igualmente, la mirada a este paisaje revela dos cosas importantes, por una parte la intensidad del proceso histórico de este mundo nuevo que en los últimos 90 años ha cubierto múltiples etapas, pudiéndose observar desde sugerentes huellas de su particular arqueología; hasta la evidencia de la tímida diversificación actual de su estructura socioeconómica, pues aunque el dúo arrozal-agua sigue siendo claramente el elemento predominante, tal como se recoge en su escudo municipal, ya no es completamente un monocultivo, pues actualmente el arroz comparte sus tablas y canales con cangrejos, peces, aves y turistas.

Y, por otra parte, este paisaje refleja lo paradójico del resultado de este proceso, ejemplarizado en el papel clave que juega actualmente el arrozal en el humedal de Doñana, donde la ingente cantidad de aves que lo frecuenta, encuentra comida y agua en buenas condiciones cuando no escasean en las marismas seminaturales.

Todos estos aspectos pueden convertir algunas de las estrategias desarrolladas en esta 
trama socioterritorial en experiencias útiles en el incierto y también paradójico mundo actual, concretamente en ese difícil trabajo de entender la necesidad de mantener los recursos naturales y usarlos con toda la equidad posible. En este caso el aprendizaje se ha centrado sobre todo en un recurso como el agua, primordial para el cultivo de arroz, para las aves, para el cangrejo, para vecinos y turistas. Un recurso del que finalmente depende toda la vida.

\section{A MODO DE CONCLUSIONES}

Aquí fue primero la solitaria inmen-
sidad del mar, y luego, ya convertido
este mar en la llanura sin horizontes
de la marisma, se produce un largo,
inacabado diálogo y esta naturaleza
viva aún hoyy desde entonces (Suárez
Japón, 1994: 5)

Siguiendo sus objetivos, con este artículo se ha pretendido mostrar como la ciudad de Sevilla, el río Guadalquivir y sus marismas comparten unos condicionantes físicos donde el agua, la inestabilidad y el dinamismo -sus motores fundamentales-, continúan activos en la actualidad.

Sobre estos condicionantes físicos compartidos, se ha ido construyendo una historia común e interrelacionada, cuyos vínculos en los últimos cien años han ido o bien reinventándose, en el caso de la ciudad y el curso urbano del río; o diluyéndose en cuanto a la triada ríociudad-marismas.

Durante ese tiempo la ciudad ha ido creciendo, colmatando el suelo ganado con la modificación de su red fluvial y cubriendo la cornisa del Aljarafe, un lugar dedicado inicialmente a lo sagrado. Sevilla se ha convertido en una gran urbe acotada en su ámbito metropolitano, un cosmos donde distintos barrios y grupos ensayan y desarrollan sus propias estrategias de funcionamiento.

Pero, considerando la idea de biorregión y el análisis que propugna, quizás no esté de más desdibujar los límites de Sevilla y mirarla en el marco físico-natural e histórico esbozado. Esto facilitará una escala más adecuada para conocer, comprender y apreciar la significación de la repetida imbricación río-ciudad-marismas, ayudando a adoptar posturas más justas y equitativas en relación a proyectos como el dragado del río. También redundaría en el conocimiento y el respeto entre lo urbano y lo rural, permeabilizando las marismas y su actual significación como un espacio productivo con importantes valores ambientales.

De forma práctica ayudaría a cumplir los Objetivos de Desarrollo Sostenible, especialmente el Objetivo 11. Ciudades y comunidades sostenibles ${ }^{15}$ y sus metas 11.4. Redoblar los esfuerzos para proteger y salvaguardar el patrimonio cultural y natural del mundo, y 11.a Apoyar los vínculos económicos, sociales y ambientales positivos entre las zonas urbanas, periurbanas y rurales fortaleciendo la planificación del desarrollo nacional y regional.

$\mathrm{Y}$, sobre todo, esa mirada permitiría reconocer e interiorizar ese permanente diálogo entre esta ciudad y el mar a través de su río, tan bien expresado en el cante de Lole Montoya: Río de mi Sevilla no te entretengas, que te espera en Sanlúcar la mar inmensa...

15 ODS. Agenda de la ONU 2030. https://www.un.org/ sustainabledevelopment/es/cities/ (consultado 10-11-2019) 


\section{BIBLIOGRAFIA Y DOCUMENTACIÓN}

BORJA, F. (2014): “Geoarqueología urbana en Sevilla”, en J. Beltrán Fortes y O. Rodríguez Gutiérrez (coords.), Sevilla Arqueológica. La ciudad en época protohistórica, antigua y andalusí. Universidad de Sevilla y Ayuntamiento de Sevilla. Sevilla: pp 276-303.

BORJA, F.; BORJA, C.; JIMÉNEZ, A. \& GARCÍA, E. (2018): "Evolución de la llanura aluvial del bajo Guadalquivir durante el Holoceno medio-superior. Geoarqueología y reconstrucción paleogeográfica de la vega de Itálica (Sevilla, España)", Boletín geológico y minero, 129(1), pp 371-420.

DARDEL, E. (2013): El Hombre y la Tierra. Naturaleza de la realidad geográfica. Madrid: Biblioteca Nueva.

DOMINGUEZ ORTIZ, A. (1991): Orto y ocaso de Sevilla. Sevilla: Universidad de Sevilla.

ESCACENA, J.L. (2014): “Sevilla Fenicia”, en J. Beltrán Fortes y O. Rodríguez Gutiérrez (coords.), Sevilla Arqueológica. La ciudad en época protohistórica, antigua y andalusí. Universidad de Sevilla y Ayuntamiento de Sevilla. Sevilla: pp 28-63.

GARCÍA, A.; DELGADO, B., OJEDA, J.F. (2007):

"Paisajes simbólicos de la ciudad de Sevilla”, en ERIA, n 73-74, pp 291-310.

GARCÍA GARCÍA, A. (2018): "Paisajes fluviales en la trama histórica de Sevilla”, en Paisajes Patrimoniales de España (Tomo III). Ministerio de Agricultura Pesca y Alimentación y Ministerio para la Transición Ecológica. Madrid: pp 1192-1208.
GONZÁLEZ, J. (1993): Las marismas del Guadalquivir: etapas de su aprovechamiento económico. Coria del Río: C.P. Antonio Cuevas. Gráficas St. María.

MORAL DE ITUARTE, L. (1991): La obra hidráulica en la cuenca baja del Guadalquivir. (Siglos XVIII-XX). Gestión del agua y ordenación del territorio. Sevilla: Universidad de Sevilla.

RODRÍGUEZ CÁRDENAS, M. (1997): Historia de la Isla Mayor del río Guadalquivir. Sevilla: Colegio Público Villafranco del Guadalquivir.

SABUCO, A. (2004). La isla del arroz amargo. Andaluces y valencianos en las marismas del Guadalquivir. Sevilla, Fundación Blas Infante.

SUAREZ, J. M. (2010): Por el río abajo: un viaje literario por las marismas del Guadalquivir. Córdoba: Almuzara.

VILLA, A.; OJEDA, J.F. (2005): “Paisajes coloniales en el Bajo Guadalquivir. Origen, evolución y carácter patrimonial". $P H$ : Boletín del Instituto Andaluz del Patrimonio Histórico, vol. 13, no 52, pp 43-54

VILLA, A.; ANDREU, C. (2013): "El arrozal respira. Valores y dinámica de los paisajes de las marismas arroceras del Guadalquivir", en Cuadernos geográficos 52 (2), pp 26-41.

VILLA, A.; ANDREU, C. (2018): "Los paisajes horizontales de las marismas arroceras del Guadalquivir", en Paisajes Patrimoniales de España (Tomo III). Ministerio de Agricultura Pesca y Alimentación y Ministerio para la Transición Ecológica. Madrid: pp 1166-1181. 


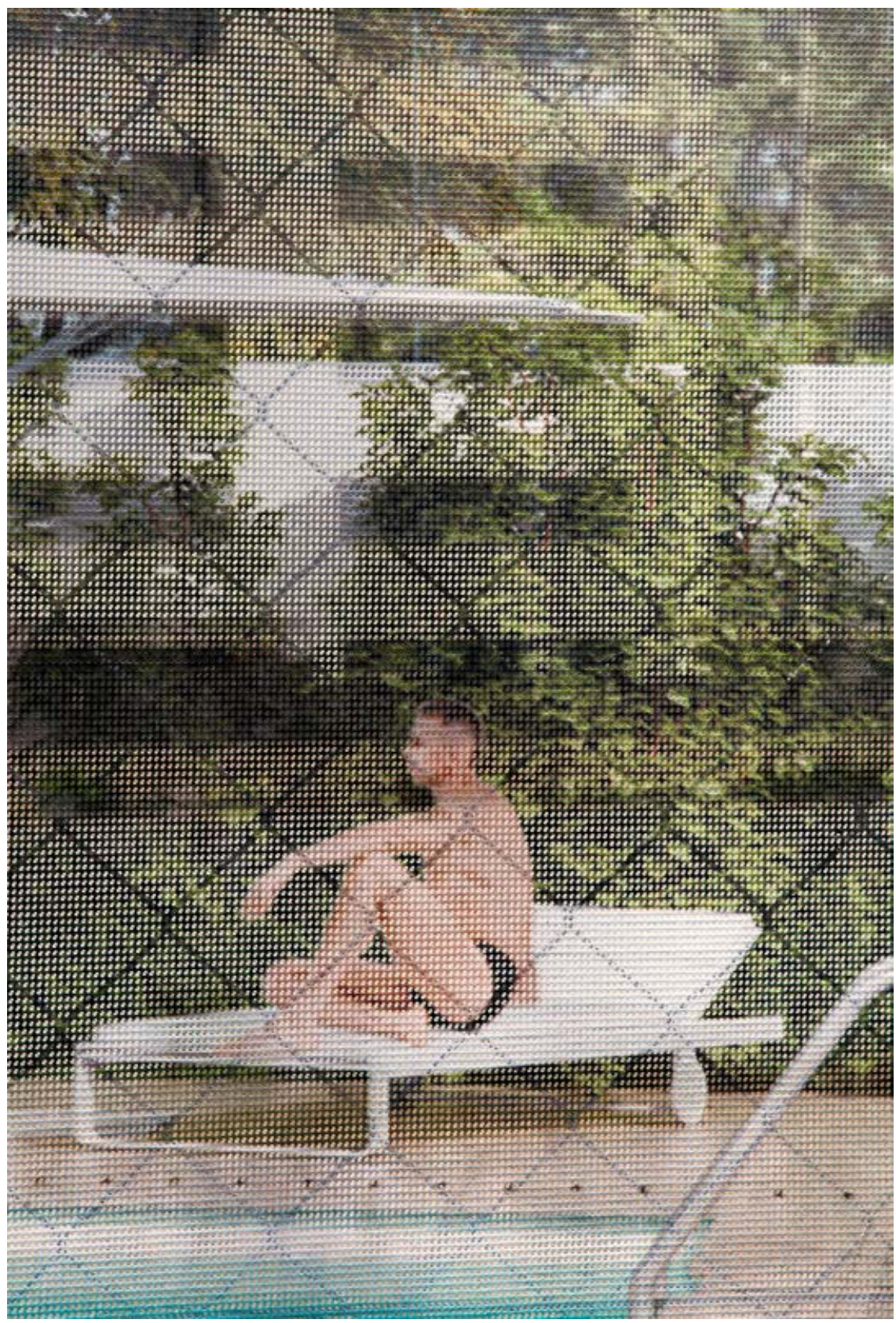

